\title{
A identidade do psicólogo do trabalho em tempos de globalização
}

\section{Roberto Heloani ${ }^{17}$}

\begin{abstract}
A psicologia do trabalho enfrenta nos dias atuais um importante desafio teórico, provocado por um duplo movimento. Por um lado - ao contrário da expectativa advogada por alguns autores, ao sugerirem o fim da categoria trabalho como conceito sociológico fundamental, ontológico mesmo - o estudo do trabalho está na passarela da moda e tudo nos leva a crer na continuidade dessa tendência, aliás, como os nossos colegas já falaram. $\mathrm{O}$ trabalho vem se metamorfoseando e tomando novos rumos, insuflando uma vasta produção científica voltada para a análise das transformações que vem sofrendo. Estudos sobre o assunto lotam as prateleiras das livrarias e das bibliotecas, fazendo emergir um considerável esforço dos pesquisadores para compreender as mudanças que nos surpreendem. E como nos surpreendem! Nesse cenário incerto e de conseqüências ainda imprevisíveis, a psicologia do trabalho vem adquirindo um novo dinamismo ao mesmo tempo em que se vê diante de novas e intrincadas questões teóricas.
\end{abstract}

Por outro lado, as teorias "disponíveis no mercado" - e são tantas - para pensar com seriedade o trabalho, vêm se mostrando cada vez mais incapazes de dar conta dos problemas apresentados pelas transformações que têm atingido o trabalho nas últimas décadas, apontando para a necessidade de se relacionar as atuais dificuldades da psicologia do trabalho à crise mais geral dos modelos teóricos que têm fundamentado as teorias organizacionais e a ciência em geral. Esta comunicação é uma modesta tentativa de colaborar nesta discussão a partir da análise de alguns mitos organizacionais, repito, mitos organizacionais, sobre os quais vem se apoiando o discurso psico-organizacional sobre as transformações pelas quais vem passando o trabalho no novo contexto mundial de reestruturação produtiva, que o Todeschini e o Bresciani já discutiram tão bem neste encontro.

Nosso ponto de partida é a constatação de que a maior parte dos estudos que têm servido de base para a psicologia organizacional partem de uma postura que restringe a análise aos aspectos materiais e tecnológicos do trabalho. Alicerçando-se em pressupostos teóricos hoje bastante discutíveis, na medida em que, ao privilegiar, de forma obsessiva, quase compulsiva - usando uma terminologia da psicodinâmica - temas como produtividade, competitividade e lucratividade, mostram-se presos a uma postura positivista calçada na análise de variáveis quantitativas que ignoram ou desprezam, às vezes as duas coisas, as implicações sociais mais amplas das transformações em curso, como bem tem demonstrado os estudos de Helena Hirata (1993 e 1995) e outros teóricos. Infelizmente, tal postura vem encobrindo uma realidade de aprofundamento das desigualdades sociais, como o Todeschini demonstrou, recolocando de forma urgente a contenda sobre o determinismo econômico e tecnológico que, conquanto esteja relativamente esquecida nos tempos de mundialização ou globalização, como quer o capital, já foi um tema bastante afeito, um tema bastante caro à psicologia do trabalho.

Talvez seja esta a oportunidade de fazermos uma breve retrospectiva histórica sobre o assunto e refletirmos, sem medo e com poucas concessões, até mesmo com algumas incertezas, sem sombra de dúvida, o que vem ocorrendo com a função e a identidade profissional do psicólogo e da própria psicologia do trabalho. É o que tentaremos fazer aqui, neste encontro, dentro do tempo previsto de vinte minutos.

\footnotetext{
${ }_{17}$ Professor da Unicamp, da Escola de Adminstração de Empresas de São Paulo da Fundação Getúlio Vargas e da Universidade São Marcos.
} 
Até a crise do paradigma taylorista-fordista de produção, o modelo de recursos humanos e a própria concepção de administração esteve articulada com a visão da engenharia, mormente com a concepção da engenharia de produção ou da engenharia chamada de "civil de minas", seja nos Estados Unidos ou na Europa Ocidental. Daí os termos "psicotecnologia" e "psicometria" conotarem o modo de pensar da maior parte dos engenheiros e dos gerentes da época. $O$ positivismo ingênuo, a noção mecanicista e o enfoque reducionista da organização são plenamente coerentes com essa terminologia. Portanto, até então, problemas relativos a liderança, seleção e fadiga, no sentido mais tradicional, eram os mais solicitados a serem resolvidos pelos psicotécnicos (Heloani, 1997).

Com a crise do fordismo e a chamada "fuga do trabalho" nos países de capitalismo avançado, a abordagem da engenharia, essa abordagem tradicional, foi perdendo espaço e começou a ser questionada paulatinamente. Ao contrário do que alguns autores afirmam, tal questionamento não foi produto de uma visão mais humanística ou de um longo e bem cuidado processo de conscientização. Não acredito nisso. Foi sim, conseqüência de uma necessidade premente de responder a uma nova estrutura econômica e a um novo modo de regulamentação social, em suma, a uma nova realidade que se apresentava e que exigia respostas rápidas, muito rápidas, por parte do capital. A administração não foi surpreendida por movimentos participacionistas, como alegam alguns. Ao contrário, na minha opinião, a busca de formas de participação foi conseqüência de uma revisão nos conceitos das próprias teorias de administração, isso sim. E por quê? Devido à necessidade de se criar um modelo mais atraente, mais sedutor, mais envolvente, onde as potencialidades do trabalhador pudessem ser mais aproveitadas na otimização das novas tecnologias - mais complexas -, que não demandam mais um "homem-boi" taylorista. Como disse Todeschini, até nós, profissionais liberais e acadêmicos, temos dificuldades de lidar com essa tecnologia. Enfim, um modelo que por essas razões fosse capaz de controlar com mais eficácia não só o corpo, mas também a mente do trabalhador. Um modelo que considerasse a subjetividade do "colaborador". Aliás, algo que Taylor já havia tentado sem muito êxito, como procurei demonstrar em minha tese de doutorado Modernidade e identidade (1991) e no livro Organização do trabalho e administração (1994). Daí a ascensão daquilo que podemos chamar de pós-fordismo.

E é justamente a partir dos anos 70 - em plena crise do modelo fordista de produção - que encontramos uma outra revisão. Onde? Na psicologia do trabalho, na psicologia organizacional. Mera coincidência? Duvido.

Uma revisão que objetivava, não uma maior emancipação em relação aos interesses do capital - ingenuidade pensar assim -, mas um novo modo de atingir os fins primordiais das organizações, quais sejam, a competitividade, a produtividade e, como não poderia deixar de ser, o lucro, como costuma dizer Roberto Campos, em seus artigos de jornal. O movimento de qualidade de vida no trabalho, que teve início naquela mesma década (70) nos países de capitalismo central e que perdura até hoje, o que ele pretende? Quais as suas intenções? Por que se investe tanto nisso? A General Motors, por exemplo, está gastando em algumas unidades da América do Norte mais em programas de qualidade de vida para seus trabalhadores, em saúde mental principalmente, do que ela despende na compra de aço. São dados da própria General Motors. Será uma atenção especial, portanto, à fisiologia do trabalhador? Ou talvez uma forma de desalienação em relação ao mesmo? Nada disso, na minha opinião.

Com a reestruturação produtiva, foi necessário reestruturar as pessoas, cooptá-las, envolvê-las, docilizá-las, como diria Foucault (1982). E tudo isso em muito pouco tempo, pouco tempo mesmo. Foi necessário reestruturar a cabeça das pessoas. Doenças até então inexistentes ou restritas a certos nichos empresariais, a certos setores da empresa, tornaramse comuns a todos e, se me permitem a ironia, democratizou-se o trabalho patogênico... Por exemplo, tem-se desvalorizado a estrutura de cargos e tarefas, articulando-se a integração 
como produto da cooperação, "achatamento da pirâmide", é o que todo mundo costuma dizer por aí. É o grande marketing nas organizações, é o que mais se fala. Isso em nível do discurso. $\mathrm{Na}$ prática, o que tem acontecido é a exigência de um trabalhador multifuncional, polivalente, que execute e tome decisões e que também arque com as conseqüências de seus erros. Só não é polivalente no que concerne ao salário, geralmente "hipovalente".

As doenças nesse tipo de organização da produção - ao contrário do que se prognosticava, era o grande mote - aumentaram e muito. Mormente as de ordem mental ou as "doenças dos nervos", como dizem os trabalhadores. Como bem profetizou Charles Handy, há vinte anos atrás - e por isso mesmo foi tido como um louco visionário por alguns e, por outros, como um péssimo matemático, vocês vão ver o porquê -, no futuro nós teríamos a seguinte equação: " $1 / 2$ × $2=3$ ". Deixem-me usar a lousa... é mais ou menos assim a equação e por isso ele foi considerado um péssimo matemático: meio vezes dois é igual a três. Realmente, além de "louco e visionário", era um "péssimo matemático". O que ele queria dizer com isso? Ele queria dizer o seguinte: que metade das pessoas trabalhariam o dobro isso ele falou há vinte anos atrás em uma palestra em Harvard - e produziriam o triplo. É claro que seus contemporâneos não gostaram da idéia, mas foi exatamente isso que ele quis dizer. E não é justamente essa a realidade atual? Não é o que está acontecendo? Está, na verdade, um pouquinho pior... É, vinte anos, coitado, ele também não era Deus... Então, você tem boa gente dentro do mercado de trabalho fazendo o dobro do que se fazia, metade esperando na fila e, através da tecnologia e da intensificação da produção, como já demonstraram o Todeschini e o Bresciani, elas produzem o triplo do que se produzia antes.

Em função disso, as organizações têm cobrado dos seus psicólogos um rápido ajustamento de suas metodologias e de suas estratégias de ação, como não poderia deixar de ser. Isso tem feito com que grande parte dos psicólogos organizacionais abracem novamente, sem nenhuma crítica e com pouquíssima reflexão, idéias, princípios e pressupostos vindos das teorias administrativas, tais como as chamadas teorias da qualidade, verdadeiro fetiche pós-moderno, pois nada mais são do que a reatualização de alguns princípios forjados na década de 30, pela Escola de Relações Humanas, adornados com uma eficiente metodologia quantitativa desenvolvida na década de 50, aproveitada nos anos 70 e aperfeiçoada nos 80 . Com o esvaziamento da área de recursos humanos, devido às reengenharias, downsizings e congêneres, alguns psicólogos estão se transformando em consultores internos, assessorando treinamentos e seleções e passando da posição de linha para a posição de staff, que além de ser, no cômputo geral, menos custosa, possui a vantagem do não envolvimento direto com o peão, com o trabalhador. Ele agora é um mediador, ele é um instrutor, um facilitador e, se tiver de tender para um lado nos dias atuais - há louváveis exceções, logicamente -, não hesitará um só segundo em demonstrar a sua empregabilidade, mesmo que para isso tenha de desempregar os seus "colaboradores". Empregabilidade também é outro fetiche, diga-se de passagem. Só que para isso faz-se necessária experiência e é justamente disso que o recém-formado carece. Ele chega, muitas vezes, cheio de boas intenções, de ilusões e decepciona-se precocemente, frustra-se e muda de área: vai para a área educacional, para a área clínica, monta um boteco, faz seja lá o que for. É triste, pois, às vezes, os melhores, justamente os mais conscientes são os que desistem mais rapidamente porque não se prestam a esse papel. Outros, heróicos, ficam.

Até pouco tempo, dizia-se que o papel do selecionador migrou para as equipes, que agora são multidisciplinares, democráticas etc. etc. Porém, isso é só meia verdade, tanto é que o selecionador, ou melhor, a seleção, no seu sentido mais tradicional, está voltando e com força. Eu arrisco um palpite a esse respeito, somente um palpite, pois essa questão específica eu não tive tempo de estudar e de pesquisar detalhadamente: eu creio que as tais equipes multidisciplinares, democráticas, não hierárquicas, possuem interesses não necessariamente coincidentes com os interesses da organização como um todo na seleção de seus membros. Daí a necessidade da ressurreição do velho selecionador, tido como "jurássico" por alguns, 
mas mais tangenciável, mais controlável pela média administração e que acaba sendo mais útil aos fins e desígnios da organização em geral do que para a equipe. Mas não nos iludamos, não interessa como será feita a seleção, se através da psicometria, de provas situacionais ou até da história de vida do "infeliz"... quer dizer, do candidato. Quem não contribuir, como profissional psicólogo, para a competitividade, tende a ser substituído, está fora. De selecionadores passam para o rol de candidatos a um novo emprego ou para a fila de desempregados. Como nas organizações pós-fordistas houve uma maquiagem no que concerne ao controle, agora o psicólogo não regula o processo. Agora o controle é por resultados, o compromisso é com a qualidade e esse profissional deve voltar sua atenção para a auto-regulação do trabalhador. Essa, sim, é a sua função. Não há nada de mais democrático ou participativo nisso em relação à concepção taylorista-fordista-fayolista, pelo menos na minha opinião. O que existe é a substituição do controle externo do desempenho pelo controle interno dos próprios funcionários, mediante um eficiente trabalho de comunicação, no qual o psicólogo, sem dúvida, poderá vir a ser protagonista, pois compete a esse profissional, agora, instruir as equipes nesse sentido.

As células de produção, ou minifábricas, como queiram, são um bom exemplo disso, pois alguns autores afirmam serem elas um verdadeiro "espaço ecumênico", onde engenheiros, técnicos e operários comungam as mesmas crenças, gozam das mesmas prerrogativas, deveres e, logicamente, convivem harmoniosamente, sem conflitos. Isso é uma farsa total! A experiência e a teoria - há um grupo francês que faz pesquisas sobre isso - têm demonstrado que quando o controle interno, individual falha, a pressão do grupo, justamente bem treinado, é extremamente eficaz, muito mais eficiente do que o supervisor em seu estilo tradicional. Competiria ao psicólogo, portanto, otimizar tal processo.

Mas não se desanimem quanto ao futuro do mercado de trabalho. De jeito nenhum. Creio que as perspectivas para a psicologia na área organizacional são excelentes, são excepcionais mesmo, pois nunca se necessitou tanto de um aparato ideológico tão bem fundamentado. Nas empresas pós-fordistas, e não só hipermodernas, a matéria principal são as pessoas. A moeda mais importante é o signo ou símbolo e a manipulação dos processos psicodinâmicos constitui a principal tecnologia. Essas são algumas das ferramentas da "empresa pós-moderna", se me permitem o neologismo. Substituíram o chicote, o supervisor (coitado do supervisor, sempre tão malhado) e os testes psicológicos pela ilusão da integração e da participação. É a tentativa de construção de uma nova subjetividade que encontra no projeto neoliberal a sementeira do individualismo e da barbárie (Heloani, 1996).

Compete a nós, psicólogos compromissados com a emancipação do ser humano, fazermos o possível e o impossível para reverter esta situação, mesmo que tal realidade seja crítica e que tenhamos poucas armas. Mas nós as temos. Uma coisa é certa: não se pode comprar discursos nem vender ilusões. Não se pode servir a dois senhores, temos de decidir.

Talvez eu tenha sido um pouco duro em relação a essa questão da psicologia, mas eu propus à Leny expressar o que realmente penso. Eu acho que há pessoas fazendo um trabalho excelente dentro das organizações. Eu trabalhei em organizações, vez por outra presto consultorias, acho que dá para fazer muita coisa. Mas também não dá, como eu falei, para vender ilusões, mesmo porque temos toda uma teoria organizacional que já o faz de uma forma excepcionalmente eficiente.

\section{Referências bibliográficas}

Foulcaut, M. (1982). Microfísica do poder. Rio de Janeiro: Graal. 
Heloani, R. (1997). A Revista de Organização Científica do Idort e o conceito de saúde mental da década de 30. In E. M. Oliveira e L. Scavone (orgs.), Trabalho, saúde e gênero na era da globalização (pp. 69-80). Goiânia: AB Editora.

Heloani, R. (1996). A mudança de paradigma no pós-fordismo: a nova subjetividade. Interações: Estudos e Pesquisas em Psicologia, Unimarco, 2, 60-76.

Heloani, R. (1994). Organização do trabalho e administração: uma visão multidisciplinar. São Paulo: Cortez.

Heloani, R. (1991). Modernidade e Identidade: os bastidores das novas formas de exercício do poder sobre os trabalhadores. Tese de Doutorado, Faculdade de Psicologia, Pontifícia Universidade Católica de São Paulo, São Paulo.

Hirata, H. (1995). Novos modelos de produção, qualidade e produtividade. Seminários e Eventos, Universidade de São Paulo, 52.

Hirata, H. (1993). Sobre o "modelo japonês". São Paulo: Edusp e Aliança Cultural Brasil-Japão.

\section{Sobre a comemoração do primeiro de maio}

$\mathrm{E}^{\mathrm{n}}$ nquanto me preparava para falar neste encontro, algumas perguntas insistiam em aparecer em busca de respostas. A primeira delas é a respeito das comemorações. O que torna comemorável uma data? Por que estamos aqui reunidos em função do primeiro de maio? Qual o valor simbólico do ritual que nos reúne?

Para cada data e cada comemoração há uma história a ser contada. A memória, quando o fato já desapareceu, reconstrói o sentido do acontecimento e dele se nutre. Encontrar esse sentido em nossa presença hoje, aqui, não significa que aquelas perguntas tenham resposta única. Ofereço a que me parece, neste momento, mais adequada.

Há mais de cem anos, trabalhadores, que lutavam pela redução da jornada de trabalho, foram massacrados em Chicago. A Segunda Internacional escolheu essa data, o primeiro dia de maio, como o "Dia do Trabalho", também porque nessa data foi convocada uma greve mundial dos trabalhadores. Parece-me que o sentido maior deste dia é, portanto, homenagear a união dos trabalhadores em torno de seus direitos, garantir que essa luta não chegou ao fim e que, a cada ano, é necessário não só lembrar os mortos daquela data, mas renovar a disposição para a luta e para a união.

Ainda não podemos ter uma perspectiva clara sobre tudo o que ocorreu neste século mas, com certeza, os trabalhadores, através de processos, às vezes violentos, às vezes não, asseguraram um certo número de direitos sociais e políticos e se tornaram conscientes da

18 Professora do Departamento de Psicologia Social e do Trabalho do Instituto de Psicologia da Universidade de São Paulo. 